\title{
Safety of Single Stage Revision Laparoscopic Sleeve Gastrectomy Compared to Laparoscopic Roux-Y Gastric Bypass after Failed Gastric Banding
}

\author{
Michał Janik $^{1,2}$ (D) Christopher Ibikunle ${ }^{3,4} \cdot$ Ahad Khan $^{4} \cdot$ Amir H. Aryaie ${ }^{1,4}$ \\ Received: 21 May 2020 / Revised: 8 September 2020 / Accepted: 11 September 2020 / Published online: 18 September 2020 \\ (C) The Author(s) 2020
}

\begin{abstract}
Background Reoperation, after failed gastric banding, is a controversial topic. A common approach is band removal with conversion to laparoscopic Roux-Y gastric bypass (LRYGB) or laparoscopic sleeve gastrectomy (LSG) in a single-step procedure.

Objective This study aimed to assess the safety of revisional surgery to LSG compared to LRYGB after failed laparoscopic adjustable gastric banding (LAGB) based on MBSAQIP Participant User File from 2015 to 2018.

Methods Patients who underwent a one-stage conversion of LAGB to LSG (Conv-LSG) or LRYGB (Conv-LRYGB) were identified in the MBSAQIP PUF from 2015 to 2017. Conv-LRYGB cases were matched (1:1) with Conv-LSG patients using propensity scoring to control for potential confounding. The primary outcome was all-cause mortality.

Results A total of 9974 patients (4987 matched pairs) were included in the study. Conv-LRYGB, as compared with conv-SG, was associated with a similar risk of mortality $(0.02 \%$ vs. $0.06 \%$; relative risk [RR], $0.33 ; 95 \%$ confidence interval [CI], 0.03 to $3.20, p=0.32)$. Conversion to LRYGB increased the risk for readmission $(6.16 \%$ vs. 3.77\%; RR, $1.63 ; 95 \% \mathrm{CI}, 1.37$ to 1.94 , $p<0.01)$; reoperation $(2.15 \%$ vs. $1.36 \%$; RR, 1.57 ; $95 \% \mathrm{CI}, 1.17$ to $2.12, \mathrm{p}=<0.01)$; leak $(1.76 \%$ vs. $1.02 \%$; RR, 1.57 ; $95 \% \mathrm{CI}$, 1.72 to $2.42, p<0.01)$; and bleeding $(1.66 \%$ vs. $1.00 \%$; RR, 1.66 ; $95 \% \mathrm{CI}, 1.7$ to $2.34, \mathrm{p}<0.01)$.

Conclusions The study shows that single-stage LRYGB and LSG as revisional surgery after gastric banding, are safe in the 30day observation with an acceptable complication rate and low mortality. However, conversion to LRYGB increased the risk of perioperative complications.
\end{abstract}

Keywords Bariatric surgery · Gastric banding · Revisional surgery $\cdot$ Laparoscopic sleeve gastrectomy $\cdot$ Laparoscopic roux-y gastric bypass $\cdot$ Metabolic and bariatric surgery accreditation and quality improvement program (MBSAQIP)

\section{Introduction}

Laparoscopic adjustable gastric banding (LAGB) was a popular bariatric procedure in the late 1990s and early 2000s [1] However, studies with long-term follow-up

Michał Janik

janiken@gmail.com

1 Bariatric Center of Excellence, Department of surgery, Texas Tech University Health Science Center, Lubbock, TX, USA

2 Department of General, Oncologic, Metabolic and Thoracic Surgery, Military Institute of Medicine, Warszawa, Poland

3 Medical College of Georgia, Augusta, GA, USA

4 Bariatric and Reflux Center, Georgia SurgiCare, Atlanta, GA, USA revealed poor weight loss outcomes and serious complications, including band erosion, slippage, and gastric pouch enlargement. [2] The majority of patients after LAGB required band removal or conversion to another bariatric procedure due to weight regain and complications. [3-7] Reoperation, after failed gastric banding, is a controversial topic. Band removal with conversion to gastric bypass or sleeve gastrectomy in a single-step procedure is one treatment option. In the analysis of MBSAQIP Participant User File (PUF) from 2015 revealed that conversion to sleeve gastrectomy might be a safer approach than gastric bypass surgery. [8] The observation was surprising because most surgeons advocate conversion to gastric bypass. We decided to replicate the study utilizing MBSAQIP data from 2015 to 2018 and addressing critical methodological flaws. 
This study aimed to assess the safety of revisional surgery to laparoscopic sleeve gastrectomy (LSG) compared to laparoscopic Roux-Y gastric bypass (LRYGB) after failed laparoscopic adjustable gastric banding (LAGB) based on MBSAQIP Participant User File from 2015 to 2018.

\section{Materials and Methods}

\section{Study Design}

This study was a retrospective registry-based analysis of patients who underwent a one-stage conversion of LAGB to LSG (Conv-LSG) or LRYGB (Conv-LRYGB). All surgeries were performed between January 1, 2015, and December 31, 2018, at centers participating in the Metabolic and Bariatric Surgery Accreditation and Quality Improvement Program (MBSAQIP). The MBSAQIP prospectively collects data on many variables, including standardized demographics, preoperative comorbidities, laboratory values, and 30-day postoperative mortality and morbidity outcomes for patients undergoing bariatric treatment in participating hospitals in the United States and Canada. [9] The definitions of variables are available in the official MBSAQIP manual. [10]

\section{Study Population - Strategy Selection}

Figure 1 shows the Strategy for Case Selection. Data analysis was performed using current recommendations and checklists for large surgical datasets. [11-13] In the first step, we identify all cases of patients who underwent sleeve gastrectomy or Roux-en-Y gastric bypass (as indicated by the use of 43,775 or 43,644 as the principal current procedural terminology [CPT] code for surgery type, according to the MBSAQIP PUF manual). In the next steps, we excluded cases whose initial surgical approach was listed as other than laparoscopic conventional. Other exclusions were: American Society of Anesthesiologists (ASA) class of 5 or missing, cases with additional unlisted CPT codes (for Miniloop Gastric Bypass, Gastric Plication, Endoscopic Therapy, Other, Intragastric Baloon), emergency cases, conditions present at the time of surgery, lack of 30-day follow-up, and BMI below 30 or over $100 \mathrm{~kg} / \mathrm{m} 2$.

Additional validation \& quality tests were performed on two cohorts to remove cases with the following criteria from the PUF 2015, PUF 2016, PUF 2017, and PUF 2018 datasets.

- Records with incomplete data regarding the highest and closest BMI before or after surgery.

- BMI variation of more than ten units between two subsequent postoperative appointments.

- Postoperative BMI > preoperative BMI.
- [only LSG patients] Reported bougie size below 30 or over 60 French. Bougie size range described in the literature is between 30 and 60 French. [14]

- [only LSG patients] Reported distance from pylorus exceeding $9 \mathrm{~cm}$. Distance $>10 \mathrm{~cm}$ was not described in the literature. [15]

Observations with missing data were excluded from the analysis.

Finally, all observations with at least one code for AGB removal $[43,774,43,772]$ listed as "Other CPT" or Concurrent CPT codes" were identified as cases of adjustable gastric band removal (AGB) with one stage conversion to Laparoscopic Sleeve Gastrectomy (Conv-LSG) or Laparoscopic Roux-Y Gastric Bypass (Conv-LRYGB). Conv-LRYGB cases were matched (1:1) with Conv-LSG patients using propensity scoring to control for potential confounding.

\section{Outcomes}

The primary outcome of the study was all-cause mortality. Secondary outcomes included:

- Operative time (OR).

- Length of hospital stay (LoS).

- Emergency department (ED) visits within 30 days postoperative.

- 30-day readmission.

-30-day intervention.

- 30-day reoperation.

- Leak rate (defined as drain present $>30$ days, organ space surgical site infection, leak-related 30-day readmission, or leak-related 30-day reoperation or intervention),

- Bleeding event (defined as bleed-related 30-day readmission, bleed-related 30-day reoperation, or transfusion required within $72 \mathrm{~h}$ postoperatively),

- 30-day morbidity.

- Including unplanned admission rate to the Intensive Care Unit within 30 days, pulmonary embolism, space surgical site infections, progressive renal insufficiency, postoperative sepsis, unplanned intubation, postoperative urinary tract infections, vein thrombosis requiring therapy, acute renal failure, postoperative cardiac arrest requiring CPR, coma over $24 \mathrm{~h}$, stroke or cerebrovascular accident, postoperative deep incisional surgical site infections, postoperative myocardial infarction, postoperative ventilation, intraoperative nerve injury, pneumonia, postoperative septic shock, unplanned intubation, Clostridium difficile infection, and wound disruption.

\section{Statistical Analysis}

Propensity scoring was used to minimize selection bias. The matching procedure was based on the probability of having conversion to LRYGB. Cases were matched with controls by 18 variables. The matching was done using a 1:1 greedy- 


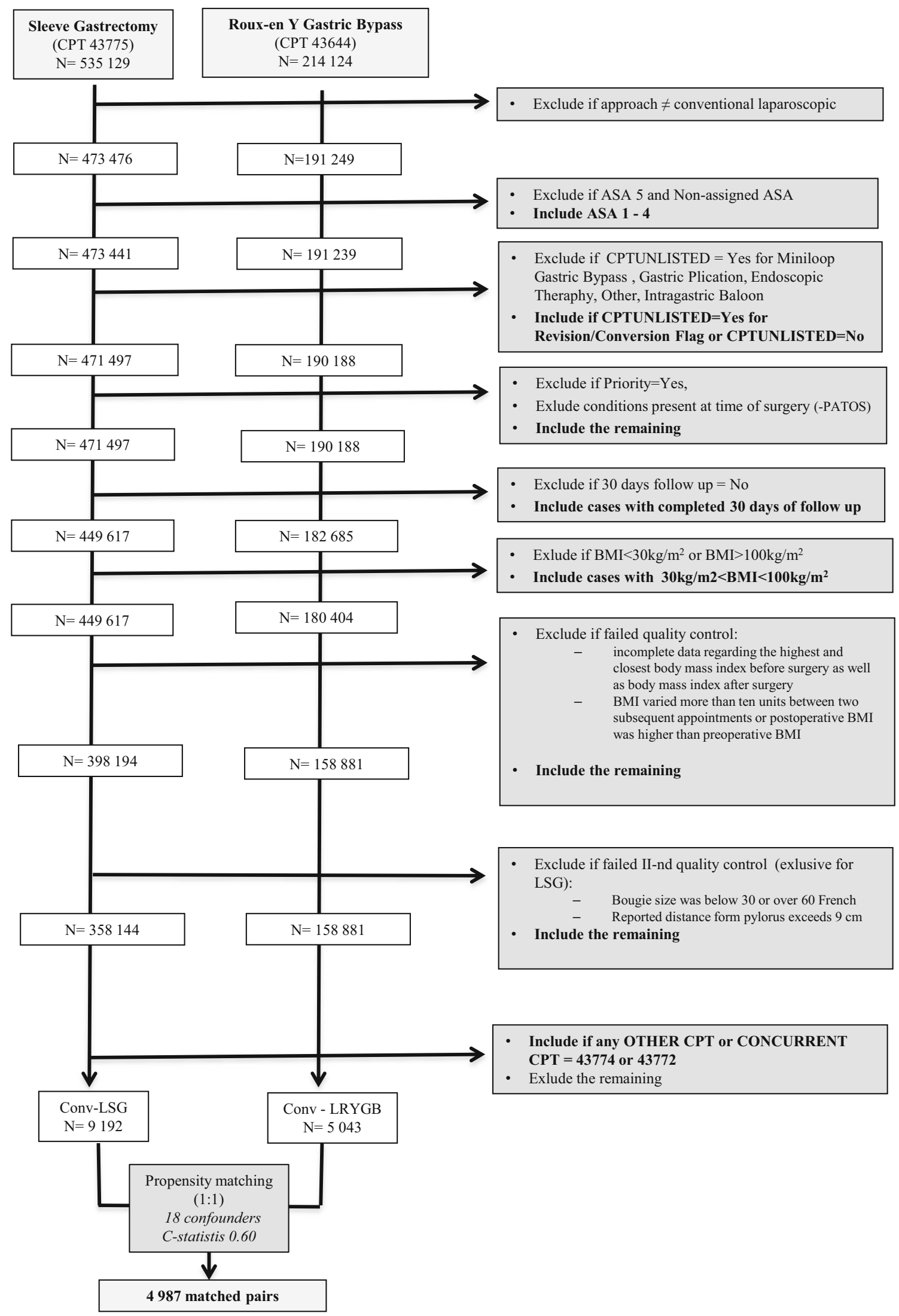

FIG. 1 Flow chart of the study 
matching algorithm, with a caliper of 0.05 standard deviation of the logit of the propensity score. [16] We assessed standardized differences for all the baseline covariates after matching to check the postmatch balance. Standardized differences below 0.1 for a given covariate indicate a small imbalance. In the matched cohort, continuous outcomes were analyzed using the paired t-test or Wilcoxon signed ranks test. Dichotomous outcomes analyzed using McNemar's analysis or Cochran-Mantel-Haenszel test. A description of effect estimates (risk ratio, RR) and 95\% confidence interval (95\% CI) was reported for category outcomes. The mean difference (or median) with $95 \%$ CI was reported for continuous variables. The analysis was performed using SAS $®$ software, University Edition (SAS 9.4 Institute Inc., Cary, NC, USA).

\section{Results}

A total of 14,235 cases were used in propensity score matching (Fig. 1). Table 1 presents the baseline characteristics of analyzed patients. Patients who were converted to LRYGB were more likely to have diabetes, sleep apnea, hypertension, hyperlipidemia, GERD, and had higher BMI. After matching, 4987 pairs were included in the final analysis. The C-statistic for the model was 0.604 . The standardized differences were < 0.1 for all variables, indicating a lack of significant differences between the two groups. (Table 2).

\section{Outcomes of Interest}

The results are presented in Table 3 . Mortality was very low and comparable between Conv-LRYGB and ConvLSG $(0.02 \%$ vs. $0.06 \%$; relative risk [RR], $0.3395 \%$ confidence interval $[\mathrm{CI}], 0.03-3.20, p=0.317)$. The most likely reason for death was listed as "Other" in all cases. Conv-LRYGB cases had significantly longer operative time (mean difference, MD $53.78[ \pm 80.18]$ minutes, $p<0.001$ ). Length of hospital stay (MD $0.41[ \pm 2.55]$ days, $\mathrm{p}<0.001)$ and the conversion rate $(0.56 \%$ vs. $0.40 \%$; RR, $1.40 ; 95 \% \mathrm{CI}, 0.79-2.48, p=0.248)$ were comparable between groups. Conversion to LRYGB increased risk for ED visits (7.74\% vs. $4.71 \%$; RR, 1.64; 95\%CI, $1.33-2.03, p<0.001)$, readmission $(6.16 \%$ vs. $3.77 \%$; RR, $1.63 ; 95 \% \mathrm{CI}, 01.37-1.94, \mathrm{p}<0.001)$, reoperations $(2.15 \%$ vs. $1.36 \%$; RR, $1.57 ; 95 \% \mathrm{CI}$, $01.17-2.12, p=0.003)$, leak $(1.76 \%$ vs. $1.02 \%$; RR, 1.72 ; 95\% CI, $1.23-2.42, \mathrm{p}<0.001)$, bleeding $(1.66 \%$ vs. $1.00 \%$; RR, 1.66; 95\%CI, 1.17-2.34, $p=0.004)$ and any medical complication $(4.97 \%$ vs. $2.35 \%$; RR, 2.12; 95\% CI, $1.70-2.63, \mathrm{p}<0.001)$. Top ten most likely reasons for readmission and reoperation are presented in Tables 4 and 5 .

\section{Discussion}

After a decade of popularity, adjustable gastric banding almost vanished. The reasons were poor weight loss outcomes and late severe complications, including band erosion, slippage, and gastric pouch enlargement. [2] Revision of failed gastric banding has become a common practice. [3-7] Choosing the next bariatric procedure is a controversial topic. Conversion to Roux-en Y gastric bypass and sleeve gastrectomy is the most common. It can be done concomitantly or as a two-stage procedure. The single-stage approach has a significant advantage - require fewer total surgeries. Thus, it is recognized as less demanding for patients. However, it is demanding for a surgeon, who needs to take down the band and fibrosis capsule before proceeding with the next step. Moreover, firing staples through the band related gastric inflammation does not seem to be the best idea. The metaanalysis by Zadeh at el. revealed that a one-stage approach was favored in the Roux-en-Y subgroup, but two-stage conversions appeared to have a lower risk of a leak in the sleeve gastrectomy subgroup. [17]

The difference was explained by the involvement of different anatomy regions in each surgery. In conversion to Roux-Y gastric bypass, a pouch creation and gastro-jejunal anastomosis can be done above the band's place. In sleeve gastrectomy, the portion of the stomach compressed by the gastric band is usually transected by the stapler. The two-stage approach gives the time needed to resolve the inflammation and thus reduces the staple line leak risk. For this reason, surgeons are afraid of doing a conversion to LSG as a single-stage procedure.

The analysis of MBSAQIP data from 2015 was the first study showing the opposite. Surprisingly, the single-stage conversion of failed gastric banding was associated with more significant morbidity and higher complication rates when converted to LRYGB versus LSG. These differences were notable regarding bleeding events, 30-day reoperation, 30-day readmission, operative time, and hospital stay. [8]

The conclusion was far from popular belief. Despite the utilization of a sizeable medical registry, the analysis did not achieve sufficient power to detect a significant leak rate.

We decided to replicate the study utilizing MBSAQIP data from 2015 to 2018 and addressing critical methodological flaws. Several issues make the present analysis unique. First, using datasets from 2015 to 2018, we obtained a large sample size. This sample size improved the power of our analysis significantly and was sufficient to detect meaningful differences. Second, Noyes et al. and Papasavas et al. stated various data quality issues in MBSAQIP datasets. [18, 19]

For this reason, we improved the strategy for the study population selection and performed additional quality checks. Third, we applied propensity score matching using the greedy algorithm. The algorithm has an important feature - it does not 
Table 1 Demographic characteristics

\begin{tabular}{|c|c|c|c|c|c|c|}
\hline \multirow[t]{2}{*}{ Characteristic } & \multicolumn{3}{|l|}{ Original cohort } & \multicolumn{3}{|l|}{ Matched cohort } \\
\hline & $\begin{array}{l}\text { Conv- } \\
\text { LRYGB } \\
N=5043 \\
\text { Mean (SD) or } 9\end{array}$ & $\begin{array}{l}\text { Conv-LSG } \\
N=9192 \\
\text { / Median Q1 ar }\end{array}$ & $\begin{array}{l}p \text { value } \\
\text { Q3 }\end{array}$ & $\begin{array}{l}\text { Conv- } \\
\text { LRYGB } \\
N=4987 \\
\text { Mean (SD) or }\end{array}$ & $\begin{array}{l}\text { Conv-LSG } \\
\mathrm{N}=4987 \\
\text { / Median Q1 an }\end{array}$ & $\mathrm{p}$ value \\
\hline Age (years) & $48.65 \pm 10.78$ & $48.27 \pm 10.84$ & 0.053 & $48.62 \pm 10.77$ & $48.51 \pm 10.98$ & 0.671 \\
\hline BMI (kg/m2) & $43.35 \pm 6.81$ & $42.03 \pm 6.85$ & $<0.001$ & $43.27 \pm 6.75$ & $43.33 \pm 7.32$ & 0.622 \\
\hline Sex (female) & 85.52 & 82.96 & $<0.001$ & 85.42 & 85.42 & 0.977 \\
\hline Race (white) & 78.78 & 76.30 & $<0.001$ & 78.70 & 78.93 & 0.799 \\
\hline GERD & 37.99 & 31.20 & $<0.001$ & 37.58 & 36.96 & 0.502 \\
\hline Pre-Op Obstructive Sleep Apnea* & 32.58 & 27.08 & $<0.001$ & 32.30 & 32.30 & - \\
\hline Pre-Op Hypertension & 47.89 & 44.88 & $<0.001$ & 47.66 & 47.02 & 0.525 \\
\hline Pre-Op Hyperlipidemia & 24.89 & 21.78 & $<0.001$ & 24.42 & 23.64 & 0.314 \\
\hline Pre-Op Diabetes Mellitus & 21.55 & 16.22 & $<0.001$ & 21.13 & 21.09 & 0.979 \\
\hline Current Smoker within One Year & 5.55 & 6.85 & $<0.023$ & 5.59 & 5.25 & 0.470 \\
\hline Preoperative Renal Insufficiency & 0.50 & 0.23 & 0.009 & 0.40 & 0.34 & 0.736 \\
\hline $\begin{array}{l}\text { History of Severe Chronic Obstructive Pulmonary } \\
\text { Disease (COPD) }\end{array}$ & 1.13 & 1.06 & 0.187 & 1.26 & 1.14 & 0.645 \\
\hline Pre-Op Vein Thrombosis Requiring Therapy & 2.24 & 1.43 & $<0.001$ & 2.15 & 1.86 & 0.346 \\
\hline History of Pulmonary Embolism & 1.17 & 1.33 & 0.436 & 1.16 & 1.24 & 0.779 \\
\hline $\begin{array}{l}\text { The medical specialty of the physician performing } \\
\text { the principal operative procedure (bariatric surgeon) }\end{array}$ & 72.91 & 73.72 & 0.302 & 73.21 & 73.69 & 0.604 \\
\hline Steroid/Immunosuppressant Use for a Chronic Condition & 1.43 & 2.06 & 0.007 & 1.44 & 1.26 & \\
\hline ASA Class & & & $<0.001$ & & & 0.302 \\
\hline I & 0.20 & 0.39 & & 0.20 & 0.14 & \\
\hline II & 22.93 & 28.02 & & 23.16 & 23.34 & \\
\hline III & 73.75 & 68.68 & & 73.57 & 73.57 & \\
\hline IV & 3.12 & 2.91 & & 3.07 & 2.95 & \\
\hline $\mathrm{V}$ & - & & & & & \\
\hline
\end{tabular}

PCI, Percutaneous coronary interventions; PTCA, Percutaneous transluminal coronary angioplasty

*- No discordant pairs, $\mathrm{p}$ value was not calculated

assign the same control subjects for different cases. At present, this method guarantees the best possible matched set. We also decided to investigate the magnitude of effect size than interpret null-hypothesis significance testing. [20] Lastly, we analyzed the most likely reasons for readmission and reoperation, which shed more light on this challenging topic. The presented analysis revealed that conversion to LRYGB did not increase the risk of 30-day death. The tendency was opposite but not statistically significant. The most likely reason for death was stated as "Other" for all cases. Overall, the conversion of failed gastric banding to either LRYGB or LSG was safe with acceptable low mortality.

Our study supported previous observations. First, the single-stage conversion is safe, and the overall mortality is very low. Second, the one-stage revision sleeve gastrectomy compared to a one-stage Roux-Y gastric bypass after failed gastric banding had a better safety profile in the short term. Our study is the first showing a higher risk for an anastomotic leak, 30-day intervention, and emergency department visits in the group converted to LRYGB. The need for conversion to open in our study was low. The analysis of most likely reasons for reoperation showed that each procedure has its profile of complication. In the group of patients after conversion to LRYGB, most reoperations were due to intestinal obstruction, whereas in Conv-LSG, the most common reason was a staple line leak.

It is essential to highlight that although conversion LAGB to LRYGB increased from $57 \%$ to $141 \%$ reoperation rate, it does not increase the overall mortality. A possible reason is a fact that complications after LRYGB are easier manageable. Small bowel obstruction (SBO) after LRYGB is commonly reported in the literature. Internal hernia and adhesions are responsible for most cases for SBO. Operative treatment remains the definitive standard and should not be delayed. [21] On the other hand, staple line after sleeve gastrectomy is challenging to manage. The occurrence of this complication 
Table 2 Standardized differences in propensity score-matched sample

\begin{tabular}{lr}
\hline Variable & $\mathrm{d}$ \\
\hline Age (years) & 0.010 \\
Body Mass Index $(\mathrm{kg} / \mathrm{m} 2)$ & 0.009 \\
Sex (female) & 0.001 \\
Race (white) & 0.005 \\
Pre-Op Hypertension & 0.013 \\
Pre-Op Diabetes Mellitus & 0.001 \\
Pre-Op Hyperlipidemia & 0.018 \\
Pre-Op Obstructive Sleep Apnea & 0.011 \\
Gastroesophageal Reflux Disease (GERD) Requiring Medication (within 30 days before surgery) & 0.013 \\
Previous Percutaneous coronary interventions (PCI) & 0.013 \\
/ Percutaneous transluminal coronary angioplasty (PTCA) & \\
Pre-Op Vein Thrombosis Requiring Therapy & 0.020 \\
History of Pulmonary Embolism & 0.007 \\
Preoperative Renal Insufficiency & 0.010 \\
History of Severe Chronic Obstructive Pulmonary Disease (COPD) & 0.011 \\
ASA Class & 0.004 \\
Steroid/Immunosuppressant Use for a Chronic Condition & 0.016 \\
Current Smoker within One Year & 0.015 \\
The medical specialty of the physician performing the principal operative procedure (bariatric surgeon) & 0.011 \\
\hline & \\
\hline
\end{tabular}

increases the mortality significantly. [22] Treatment requires time. According to Sakran, the median time to staple line leak closure is 40 days. [23] It is much more than the median time reported for leaks after gastric bypass surgery, 13 days. [24]

Likely, the 30-day observation period stated in the MBSAQIP can not capture the outcome in the cases where the leak after conversion to LSG was present regarding reoperation, intervention, and death. Even though the leak was the most likely reason for reoperation in the Conv-LSG group, the incidence was lower than in Conv-LRYGB patients. In our analysis, laparoscopic sleeve gastrectomy after gastric banding showed a leakage rate of $1.02 \%$, which was higher than reported from primary LSG in the MBASQIP database ranging from 0.6 to $0.9 \%$. [15, 25]

In our study, patients converted to LRYGB had an anastomotic leakage percentage of $1.76 \%$. It corresponded to the analysis from 2015 and was higher than the reported rate for primary LRYGB in MBSAQIP analysis (0.6\%). [26]

Our study showed that conv-LRYGB increased the risk of short term complications in comparison to conv-LSG

Table 3 Main outcomes of interes

\begin{tabular}{|c|c|c|c|c|c|c|}
\hline \multirow{2}{*}{$\begin{array}{l}\text { Outcomes } \\
\text { Continuous }\end{array}$} & \multicolumn{2}{|c|}{$\begin{array}{l}\text { CONV - LRYGB } \\
N=4987\end{array}$} & \multicolumn{2}{|c|}{$\begin{array}{l}\text { CONV - LSG } \\
N=4897\end{array}$} & \multirow[t]{2}{*}{ Mean difference \pm SD } & \multirow[t]{2}{*}{$P$-value } \\
\hline & \multicolumn{2}{|c|}{ Mean \pm SD } & \multicolumn{2}{|c|}{ Mean \pm SD } & & \\
\hline Length of bariatric procedure (min) & \multicolumn{2}{|c|}{$162.28 \pm 64.94$} & \multicolumn{2}{|c|}{$108.45 \pm 46.78$} & $53.78 \pm 80.18$ & $<0.001$ \\
\hline Length of hospital stay (days) & \multicolumn{2}{|c|}{$2.05 \pm 1.53$} & \multicolumn{2}{|c|}{$1.63 \pm 2.04$} & $0.41 \pm 2.55$ & 1.000 \\
\hline Categorical & $\%$ & $N$ & $\%$ & $N$ & Risk Ratio [95\% CI] & $P$-value \\
\hline Death within 30 days & $0.02 \%$ & 1 & $0.06 \%$ & 3 & RR: $0.33[0.03-3.20]$ & 0.317 \\
\hline Conversions to open approach & $0.56 \%$ & 28 & $0.40 \%$ & 20 & RR: $1.40[0.79-2.48]$ & 0.248 \\
\hline Emergency department (ED) visits within the 30 days postoperative & $7.74 \%$ & 217 & $4.71 \%$ & 132 & RR: $1.64[1.33-2.03]$ & $<0.001$ \\
\hline Inpatient readmission(s) by midnight of POD 30 & $6.16 \%$ & 307 & $3.77 \%$ & 188 & RR: 1.63 [1.37-1.94] & $<0.01$ \\
\hline Interventions performed within 30 days & $3.19 \%$ & 159 & $1,32 \%$ & 66 & RR: 2.41 [1.82-3.19] & $<0.001$ \\
\hline Reoperations performed within 30 days & $2.15 \%$ & 107 & $1.36 \%$ & 68 & RR: 1.57 [1.17-2.12] & 0.003 \\
\hline Leak within 30 days & $1.76 \%$ & 88 & $1.02 \%$ & 55 & RR: 1.72 [1.23-2.42] & 0.001 \\
\hline Bleeding within 30 days & $1.66 \%$ & 83 & $1.00 \%$ & 50 & RR: 1.66 [1.17-2.34] & 0.004 \\
\hline Any medical complications within 30 days & $4.97 \%$ & 248 & $2.35 \%$ & 117 & RR: 2.12 [1.70-2.63] & $<0.001$ \\
\hline
\end{tabular}


Table 4 Top 10 the most likely reasons for readmission

\begin{tabular}{|c|c|c|c|c|c|}
\hline $\begin{array}{l}\text { CONV-LRYGB } \\
N=\mathbf{3 0 7}\end{array}$ & & & $\begin{array}{l}\text { CONV-LSG } \\
N=188\end{array}$ & & \\
\hline Reason & $\mathbf{N}$ & $\%$ & Reason & $\mathbf{N}$ & $\%$ \\
\hline $\begin{array}{l}\text { 1. Nausea and } \\
\text { Vomiting, Fluid, } \\
\text { Electrolyte, or } \\
\text { Nutritional } \\
\text { Depletion }\end{array}$ & 60 & 19.54 & $\begin{array}{l}\text { 1. Nausea and } \\
\text { Vomiting, Fluid, } \\
\text { Electrolyte, or } \\
\text { Nutritional } \\
\text { Depletion }\end{array}$ & 45 & 23.94 \\
\hline $\begin{array}{l}\text { 2. Abdominal Pain, Not } \\
\text { Otherwise Specified }\end{array}$ & 46 & 14.98 & 2. Other & 25 & 13.30 \\
\hline $\begin{array}{l}\text { 3. Intestinal } \\
\text { Obstruction }\end{array}$ & 33 & 10.75 & $\begin{array}{l}\text { 3. Anastomotic/Staple } \\
\text { Line Leak }\end{array}$ & 24 & 12.77 \\
\hline 4. Other & 29 & 9.45 & $\begin{array}{l}\text { 4.Abdominal Pain, Not } \\
\text { Otherwise Specified }\end{array}$ & 21 & 11.17 \\
\hline $\begin{array}{l}\text { 5. Anastomotic/Staple } \\
\text { Line Leak }\end{array}$ & 16 & 5.21 & $\begin{array}{l}\text { 5. Other Abdominal } \\
\text { Sepsis }\end{array}$ & 12 & 6.48 \\
\hline 6. Bleeding & 16 & 5.21 & $\begin{array}{l}\text { 6. Strictures / Stomal } \\
\text { Obstruction }\end{array}$ & 12 & 6.38 \\
\hline $\begin{array}{l}\text { 7. Other Abdominal } \\
\text { Sepsis }\end{array}$ & 14 & 4.56 & $\begin{array}{l}\text { 7. Vein Thrombosis } \\
\text { Requiring Therapy }\end{array}$ & 11 & 5.85 \\
\hline $\begin{array}{l}\text { 8. Wound infection / } \\
\text { Evisceration }\end{array}$ & 14 & 4.56 & 8. Bleeding & 7 & 3.72 \\
\hline $\begin{array}{l}\text { 9. Strictures / Stomal } \\
\text { Obstruction }\end{array}$ & 12 & 3.91 & 9. Pneumonia & 5 & 2.66 \\
\hline 10. Infection/Fever & 11 & 3.58 & $\begin{array}{l}\text { 10. Pulmonary } \\
\text { Embolism }\end{array}$ & 5 & 2.66 \\
\hline
\end{tabular}

Top 10 for $\mathrm{LRYGB}=81,76 \% / \mathrm{LSG}=88.83 \%$

significantly. However, the effect size was mainly moderate, and it is difficult to determine if both procedures are comparable in terms of long-term complications because there is not enough data.
What is more, reports are indicating the significant benefit of conversion to LRYGB. The recent meta-analysis showed that conversion to LRYGB was associated with better weight loss at 12 and 24 months compared to conversion to LSG. [27]

Our study's essential message is the following: both conversions of failed gastric banding have an excellent safety profile with acceptable complications rate. Although conversion to Laparoscopic Roux-Y gastric bypass increased the risk for short-term complications, the effect size is moderate. In this situation, the risk profile should not outweigh the weight loss benefits.

Our study has a few significant limitations. First, the MBSAQIP database is observational. The association between adverse events should be tested prospectively in a controlled environment to evaluate a potential causal relationship. However, considering the low rate of adverse events, it would be challenging to conduct a randomized control study with enough power to show a difference. Second, we could not assess the efficacy of conversions because of the lack of data on weight loss outcomes and comorbidities improvement. MBSAQIP database does not provide sufficient data on significant intraoperative variations in techniques. For this reason, we were not able to assess some essential technical details. Similarly, significant factors that could affect risk profile, such as operative findings and indications, were also not included.

\section{Conclusion}

Our study shows that single-stage laparoscopic Roux-Y gastric bypass and laparoscopic sleeve gastrectomy as revisional

Table 5 Top 10 the most likely reasons for reoperation

\section{TOP 10 for Reoperation}

\begin{tabular}{|c|c|c|c|c|c|}
\hline \multicolumn{3}{|l|}{$\begin{array}{l}\text { CONV-LRYGB } \\
N=107\end{array}$} & \multicolumn{3}{|l|}{$\begin{array}{l}\text { CONV-LSG } \\
N=68\end{array}$} \\
\hline Reason & $\mathbf{N}$ & $\%$ & Reason & $\mathbf{N}$ & $\%$ \\
\hline 1. Intestinal Obstruction & 31 & 28.97 & 1. Anastomotic/Staple Line Leak & 17 & 25.00 \\
\hline 2. Anastomotic/Staple Line Leak & 13 & 12.15 & 2. Other & 14 & 20.59 \\
\hline 3. Bleeding & 13 & 12.15 & 3. Bleeding & 13 & 19.12 \\
\hline 4. Other & 13 & 12.15 & 4. Strictures / Stomal Obstruction & 7 & 10.29 \\
\hline 5. Incisional Hernia & 7 & 6.54 & 5. Other Abdominal Sepsis & 5 & 7.35 \\
\hline 6. Wound Infection / Evisceration & 6 & 5.61 & 6. Wound Infection / Evisceration & 4 & 5.88 \\
\hline 7. Abdominal Pain, Not Otherwise Specified & 4 & 3.74 & 7. Intestinal Obstruction & 2 & 2.94 \\
\hline 8. Internal Hernia & 4 & 3.74 & 8. Nausea and Vomiting, Fluid, Electrolyte, or Nutritional Depletion & 2 & 2.93 \\
\hline 9. Other Abdominal Sepsis & 4 & 3.74 & 9. Abdominal Pain, Not Otherwise Specified & 1 & 1.47 \\
\hline 10. Planned Surgery & 3 & 2.80 & 10. GI perforation & 1 & 1.47 \\
\hline
\end{tabular}

Top 10 for $\mathrm{LRYGB}=91,59 \% / \mathrm{LSG}=97.06 \%$ 
surgery after gastric banding, are safe in the 30-day observation with an acceptable complication rate and low mortality. The conversion to LRYGB is more demanding and increases the risk of leak rate, bleeding events, reoperation, intervention, readmission, longer operative time and more extended hospital stay, emergency department visits, and morbidity. However, the effect size for the increase in risk was moderate. The essential message is that increase in complications rate did not result in higher mortality. The decision about the type of procedure should be based on individual patient's risksbenefits assessment.

\section{Compliance with Ethical Standards}

Conflict of Interest The authors declare that they have no conflict of interest.

Ethical Statement All procedures involving human participants were performed in accordance with the ethical standards of the institutional and/or national research committee and with the 1964 Helsinki Declaration and its later amendments or comparable ethical standards.

Consent Statement For this type of study consent was not required.

Open Access This article is licensed under a Creative Commons Attribution 4.0 International License, which permits use, sharing, adaptation, distribution and reproduction in any medium or format, as long as you give appropriate credit to the original author(s) and the source, provide a link to the Creative Commons licence, and indicate if changes were made. The images or other third party material in this article are included in the article's Creative Commons licence, unless indicated otherwise in a credit line to the material. If material is not included in the article's Creative Commons licence and your intended use is not permitted by statutory regulation or exceeds the permitted use, you will need to obtain permission directly from the copyright holder. To view a copy of this licence, visit http://creativecommons.org/licenses/by/4.0/.

\section{References}

1. Gonzalez-Heredia R, Masrur M, Patton K, et al. Revisions after failed gastric band: sleeve gastrectomy and roux-en-Y gastric bypass. Surg Endosc Other Interv Tech. 2015;29:2533-7.

2. Chevallier J, Zinzindohoué F, Blanche J, Berta J, Altman J, Cugnenc P. Complications after Laparoscopic Adjustable Gastric Banding for Morbid Obesity : Experience with 1,000 Patients over 7 Years. 2004;407-14.

3. Spivak H, Abdelmelek MF, Beltran OR, Ng AW, Kitahama S. Long-term outcomes of laparoscopic adjustable gastric banding and laparoscopic Roux-en-Y gastric bypass in the United States. Surg. Endosc. [Internet]. 2012;26:1909-19. Available from: http:// link.springer.com/10.1007/s00464-011-2125-z

4. Suter M, Calmes J, Paroz a, Giusti V. A 10-year Experience with Laparoscopic Gastric Banding for Morbid Obesity: High LongTerm Complication and Failure Rates. Obes. Surg. 2006;16:82935.

5. Angrisani L, Cutolo PP, Formisano G, Nosso G, Vitolo G. Laparoscopic adjustable gastric banding versus Roux-en-Y gastric bypass: 10-year results of a prospective, randomized trial. Surg.
Obes. Relat. Dis. [Internet]. Elsevier; 2013;9:405-413. Available from: https://doi.org/10.1016/j.soard.2012.11.011

6. Kowalewski PK, Olszewski R, Kwiatkowski A, Gałązka-Świderek N, Cichoń K, Paśnik K. Life with a Gastric Band. Long-Term Outcomes of Laparoscopic Adjustable Gastric Banding-a Retrospective Study. Obes. Surg. [Internet]. 2016;1-4. Available from: http://link.springer.com/10.1007/s11695-016-2435-2

7. O Brien PE, MacDonald L, Anderson M, Brennan L, Brown WA. Long-term outcomes after bariatric surgery. Ann. Surg. [Internet]. 2013;257:87-94. Available from: http://content.wkhealth.com/ linkback/openurl?sid=WKPTLP:landingpage $\& a n=00000658$ 201301000-00013

8. Janik MR, Rogula TG, Mustafa RR, et al. Safety of revision sleeve Gastrectomy compared to roux-Y gastric bypass after failed gastric banding: analysis of the MBSAQIP. Ann. Surg. [internet]. United States; 2019;269:299-303. Available from. https://www.ncbi.nlm. nih.gov/pubmed/29095195

9. The Metabolic and Bariatric Surgery Accreditation and Quality Improvement Program. User Guide for the MBSAQIP ®. Participant Use Data File. 2015:2011.

10. MBSAQIP. 2015 MBSAQIP ® PUF Variables \& Definitions Manual. 2015;

11. Haider AH, Bilimoria KY, Kibbe MR. A checklist to elevate the science of surgical database research. JAMA Surg United States. 2018;153:505-7.

12. PLOS Medicine Editors. Observational studies: getting clear about transparency. PLoS Med. 2014;11:e1001711.

13. Telem DA, Dimick JB. Practical guide to surgical data sets: metabolic and bariatric surgery accreditation and quality program (MBSAQIP). JAMA Surg. 2018;153:766-7.

14. Aurora AR, Khaitan L, Saber AA. Sleeve gastrectomy and the risk of leak: a systematic analysis of 4,888 patients. Surg Endosc Other Interv Tech. 2012;26:1509-15.

15. Berger ER, Clements RH, Morton JM, et al. The impact of different surgical techniques on outcomes in laparoscopic sleeve Gastrectomies. Ann Surg [Internet]. 2016;264:464-73. Available from: http://insights.ovid.com/crossref?an=00000658-20160900000009

16. Faries D, Leon AC, Haro JM, Obenchain RL. Analysis of Observational Health Care Data Using SAS. 1st ed. SAS Institute; 2014.

17. Zadeh J, Le C, Ben-David K. Safety of adjustable gastric band conversion surgery: a systematic review and meta-analysis of the leak rate in 1- and 2-stage procedures. Surg. Obes. Relat. Dis. [internet]. United States; 2019;S1550-7289(19)31138-4. Available from. https:/www.ncbi.nlm.nih.gov/pubmed/31937489

18. Noyes KK, Myneni AA, Schwaitzberg SD, Hoffman AB. Quality of MBSAQIP data: bad luck, or lack of QA plan? Surg. Endosc. [Internet]. Springer US; 2019; Available from: http://link.springer. com/10.1007/s00464-019-06884-x

19. Papasavas P, Seip RL, Stone A, et al. Robot-assisted sleeve gastrectomy and roux-en-y gastric bypass: results from the metabolic and bariatric surgery accreditation and quality improvement program data registry. Surg. Obes. Relat. Dis. [internet]. 2019/04/13. United States; 2019;15:1281-90. Available from. https://www. ncbi.nlm.nih.gov/pubmed/31477248

20. George BJ, Beasley TM, Brown AW, et al. Common scientific and statistical errors in obesity research. Obesity (silver spring). [internet]. 2016;24:781-90. Available from. https://www.ncbi.nlm.nih. gov/pubmed $/ 27028280$

21. Clapp B. Small bowel obstruction after laparoscopic gastric bypass with nonclosure of mesenteric defects. JSLS J. Soc. Laparoendosc. Surg. [internet]. Society of Laparoendoscopic Surgeons; 2015;19: e2014.00257-e2014.00257. Available from. https://www.ncbi.nlm. nih.gov/pubmed/25848176 
22. Benedix F, Poranzke O, Adolf D, et al. Staple line leak after primary sleeve Gastrectomy-risk factors and mid-term results: do patients still benefit from the weight loss procedure? Obes. Surg. [internet]. United States; 2017;27:1780-8. Available from. https://www.ncbi. nlm.nih.gov/pubmed/28078641

23. Sakran N, Goitein D, Raziel A, et al. Gastric leaks after sleeve gastrectomy: a multicenter experience with 2,834 patients. Surg. Endosc. [internet]. 2012/06/30. Germany; 2013;27:240-5. Available from. https://www.ncbi.nlm.nih.gov/pubmed/22752283

24. Jacobsen HJ, Nergard BJ, Leifsson BG, et al. Management of suspected anastomotic leak after bariatric laparoscopic roux-en-y gastric bypass. Br J Surg. 2014;101:417-23.

25. Mocanu V, Dang J, Ladak F, et al. Predictors and outcomes of bleed after sleeve gastrectomy: an analysis of the MBSAQIP data registry. Surg. Obes. Relat. Dis. [internet]. 2019/08/10. United States; 2019;15:1675-81. Available from. https://www.ncbi.nlm.nih.gov/ pubmed/31590999

26. Mocanu V, Dang J, Ladak F, et al. Predictors and outcomes of leak after roux-en-Y gastric bypass: an analysis of the MBSAQIP data registry. Surg. Obes. Relat. Dis. [internet]. 2019/01/26. United States; 2019;15:396-403. Available from. https://www.ncbi.nlm. nih.gov/pubmed/30782473

27. Wu C, Wang F-G, Yan W-M, et al. Clinical outcomes of sleeve Gastrectomy versus roux-en-Y gastric bypass after failed adjustable gastric banding. Obes. Surg. [internet]. United States; 2019;29: 3252-63. Available from. https://www.ncbi.nlm.nih.gov/pubmed/ 31292884

The American College of Surgeons Metabolic and Bariatric Surgery Accreditation and Quality Improvement Program and the centers participating in the ACS MBSAQIP are the source of the data used herein; they have not verified and are not responsible for the statistical validity of the data analysis or the conclusions derived by the authors.?

Publisher's Note Springer Nature remains neutral with regard to jurisdictional claims in published maps and institutional affiliations. 